\title{
Assessment of the Performance of a Small Capacity SI Engine Fuelled with Model Lean Mixture of Biogas*
}

\author{
G. Przybyla**1, A. Szlek ${ }^{2}$, L. Ziolkowski ${ }^{3}$ \\ Institute of Thermal Technology \\ Konarskiego 22, 44-100, Gliwice, Poland \\ e-mail: ${ }^{1}$ gprzybyla@ polsl.pl, ${ }^{2}$ aszlek@ @olsl.pl, ${ }^{3}$ lziolskowski@polsl.pl
}

\begin{abstract}
In this paper the results of the experimental study on the SI engine using biogas are presented. The experiments were carried out on a petrol engine with a low engine displacement. Typical SI engine was selected in order to evaluate the potential application of gaseous fuel (i.e. biogas). These types of engines are available on a wide scale and commonly used in automotive sector because of the low purchase price and operating costs. It is expected that after minor modifications, the engine can easily operate in low power co-generation mode. In an experimental part of this paper a complete study of the biogas combustion is presented and compared with the results for natural gas in the same unmodified petrol engine (without modification to its combustion system). The main objective was to compare and evaluate the performance, efficiency, and environmental impact of the engine under lean air/fuel mixture conditions when using alternative fuel, i.e. biogas and natural gas.
\end{abstract}

\section{Keywords: Global warming; spark ignition (SI) engine; biogas; exhaust emission; indicated efficiency.}

\section{Introduction}

Running out of fossil fuels and increase in climate change are the main reason to seek alternative methods for more efficient use of fuel energy and increase in application of renewable resources. That is the resources which do not emit greenhouse gases and contribute to major reduction of emissions (considering fuel sustainability and carbon life cycle). Among all the types of renewable fuels, biomass is considered the most important with respect to the Polish climate and geographical conditions (Berggren et al., 2008; Igliński et al., 2011; Leszczynski et al., 1997).

Liquid fuels derived from biomass processing such as vegetable oils (i.e. fatty acid methyl esters - FAME) and alcohols are currently common in use as a blend component or additive to conventional fuels (McKendry, 2002; Mancaruso et al., 2011; Silva et al., 2013). These fuels play an important role and can be considered as a possible alternative for the internal combustion engines. When considering biomass processing technologies, fermentation process is one of the possible options for biogas production and consequently energetic use of biomass.

A possible further alternative is the production of landfill gas using urban organic wastes which in terms of composition is comparable to biogas. Both gases consist mainly of methane and carbon dioxide with some traces of other gases. It should be highlighted that methane is a greenhouse gas that can similarly to carbon dioxide contributes to global warming and climate change. The comparative impact of $\mathrm{CH}_{4}$ on climate change is over 20 times greater than $\mathrm{CO}_{2}$ over a 100-year period. (Bade et al., 2008). Therefore, utilization of landfill gas for the purposes of power generation will lead to reduction of emissions released into the atmosphere (i.e. emissions from municipal solid waste) and provide potential benefits and additional revenues to the local government. Furthermore, the value of municipal solid wastes is rising worldwide every year.
Depending on the country of origin, the organic part of the urban waste represents approx. 20 to $80 \%$ (Curry \& Pillay, 2012; Adhikari et al., 2006; Poulsen et al., 2013).

The composition of landfill gas depends directly on the type of waste utilized, environmental parameters and location of the landfill. The detailed composition of biogas depends mainly on the type of technology applied in the biomass processing (i.e. biogas plant) and the stock of organic matter. The main components of biogas and landfill gas are methane and carbon dioxide, with a typical range of about $50 \div 75 \%$ of $\mathrm{CH}_{4}$ and $25 \div 45 \%$ of $\mathrm{CO}_{2}$, respectively (dry basis, percent by volume), all other elements such as $\mathrm{H}_{2}, \mathrm{CO}, \mathrm{N}_{2}, \mathrm{O}_{2}, \mathrm{NH}_{3}, \mathrm{H}_{2} \mathrm{~S}$ represent an insignificantly small fraction of the total. It should be highlighted that methane fraction is an important parameter affecting the characteristic of combustion process in internal combustion engines. It has been reported that even though relatively small (below 1\%), the fraction of hydrogen in biogas has a positive effect on the combustion process (Igliński et al., 2011). It is worth noting that hydrogen sulfide $\left(\mathrm{H}_{2} \mathrm{~S}\right)$ in biogas has a negative impact on operation of the engine, leading in extreme cases to mechanical failure of system components. This is an important aspect with respect to the internal combustion engines operation that is outside of the scope of this paper.

\section{Combustion of Gas Fuels in IC Engine \\ 2.1 Types of Reciprocating Engines Burning Biogas}

Biogas and landfill gas can be used to power internal combustion (IC) engines with both spark ignition (SI) and compression ignition (CI). The diesel engine uses heat of compression to initiate ignition to burn the pilot fuel dose injected directly into the combustion chamber (or into the pre-chamber). In case of pilot fuel injection systems applied in diesel engines the use of biofuel is preferred since all the

\footnotetext{
* This paper is an updated version of a paper published in the CPOTE 2012 proceedings. It is printed here with permission of the authors and organizers.
} 
energy produced is considered as renewable. This is also important with respect to the current regulations.

In this paper combustion of lean and stoichiometric gas fuel mixtures in typical SI engine has been studied experimentally. It is worth noting that combustion of lean mixtures can provide a substantial increase in energy efficiency of the internal combustion engine. The following key factors listed below affect the energy efficiency when using lean gas-fuel mixtures:

- Lower pumping losses at a given engine speed is termed part load operation;

- Reduced wall heat loss of the combustion chamber since the overall gas temperature is considerably lower compared to that of stoichiometric mixtures;

- Reduced dissociation of the high temperature combustion gases that more chemical energy of fuel is released when the piston is close to the top dead centre (TDC) position during expansion phase.

During experiments the engine was fuelled with natural gas coming from the gas grid and model biogas consisted of $60 \%$ of methane and $39 \%$ of carbon dioxide. The more detailed properties of tested fuels are presented in Table 1.

Table 1. The Main Properties of Tested Fuels.

\begin{tabular}{ccc}
\hline Fuel & Natural Gas & Biogas \\
\hline $\mathrm{LHV}, \mathrm{MJ} / \mathrm{m}^{3} \mathrm{n}$ & 35 & 20.8 \\
Composition, & $\mathrm{CH}_{4}=98.5, \mathrm{CO}_{2}=0.1, \mathrm{~N}_{2}$ & $\mathrm{CH}_{4}=60, \mathrm{CO}_{2}=39, \mathrm{~N}_{2}$ \\
$\%$ & $\begin{array}{c}=0.8, \\
\text { other: ethane, propane, } \\
\text { butane }\end{array}$ & $\begin{array}{c}\text { other: ethane, propane, } \\
\text { butane }\end{array}$ \\
\hline
\end{tabular}

\subsection{Combustion Characteristic and Performance in Spark Ignition (SI) Engines}

In order to ignite a stoichiometric air-petrol mixture, the spark ignition energy of approximately $0.2 \mathrm{MJ}$ is required. In the case of combustion of gaseous fuel produced by the anaerobic fermentation the discharge energy required to ignite the mixture depends on the fuel methane fraction content (volume fraction). The minimum energy necessary to ignite pure methane is approximately equal to $0.29 \mathrm{MJ}$ (Das et al., 2000). It should be highlighted that biogas contain a substantial amount of nitrogen (inert gas), thus its proper ignition requires the use of high-energy ignition system with higher discharge energy. The traditional ignition system can produce a spark with a discharge energy approximately 10 times higher than theoretically needed (of about 30-50 MJ - for gasoline) to ignite the air fuel mixture (Stone, 1999; Heywood, 1988). It is in order to avoid the in cylinder misfire. The presence of sufficient spark energy for ignition assures the correct flame kernel development and also has fundamental impact on the initial process of flame front creation. The engine employed in the experimental test has been equipped with a transistorized ignition system with higher energy spark discharge.

The propagation speed of laminar flame stoichiometric gas mixtures is slightly lower compared to petrol-air mixtures (Weaver, 1989). The laminar flame speed of selected fuel-air mixtures (at $\lambda=1$ ) is equal to approximately $0.4 \mathrm{~m} / \mathrm{s}$ and $0.38 \mathrm{~m} / \mathrm{s}$ for petrol and methane, respectively (White et., 2006; Das et al., 2000). With respect to biogas, this value is lower and mainly determined by the carbon dioxide fraction content in the fuel. Therefore, higher carbon dioxide fraction content in biogas in relation to methane provide lower combustion speeds.
The flame propagation velocity decreases with an increase in excess air ratio (Ayala et al., 2006). It should be noted that low flame propagation speeds are particularly undesirable during the engine operating at partial loads. Low combustion speed and incorrect ignition angle will have an effect on incomplete combustion process. Therefore, it seems to be crucial to determine the impact of spark ignition timing on the combustion process in the engine fuelled with lean mixtures of biogas and natural gas. The combustion of lean mixtures can be less stable. Furthermore, one of the problematic issue with respect to lean mixtures combustion is their difficulty to ignite and slower flame propagation. Under certain conditions the lean mixture may have a greater tendency to incomplete combustion. The interrelation of these factors leads to an increased variations of the pressure profiles in the successive cycles of the engine operation.

\section{Overview of the Engine Test Bench and Plan of Experiment \\ 3.1 Engine Test Bench}

An overview of the engine test bench and measuring equipment is presented in Figure 1. The main components of the experimental set up include:

- Three cylinders SI engine with a capacity of $796 \mathrm{~cm}^{3}$ and compression ratio equal to 9.3. The engine is without turbocharging and was originally powered by petrol. For the purpose of experiment and possibility of gaseous fuel application, the control and power supply system of the engine have been modified.

- Electric motor with the power take-off system, capable of operating in two modes, the motor and generator. The main purpose of this system is to start the engine and then to apply load on the selected point of the operating cycle

- High-pressure cylinders with gas mixtures and dual stage gas regulators,

- Measuring devices for flow rate, temperature and pressure evaluation including: rotameters, manometers and thermocouples.

During the experiment, the operation of the engine was controlled using Electronic Control Unit (ECU). This type of device driver has the capability to program and monitor engine operational parameters, i.e. pre-programmed ignition timing maps and mixture composition. The composition of the mixture was controlled using the signal from lambda sensor, which can operate in a closed loop mode with the controller. The controller also has adjustable spark plug discharge energy by changing the loading time of high voltage coils.

The gas fuel was supplied to the engine through the gas mixer. Two mixers were selected to fuelling the engine by air-gas mixture, separately for natural gas and for biogas. The volumetric flow of natural gas and $\mathrm{CO} 2$ has been manually adjusted by special valve to obtain demanded biogas mixture composition and value of air excess ratio during combustion. Value of air excess ratio was controlled by wideband lambda sensor. The volumetric flows of the gases were measured by rotameter equipped in temperature and pressure sensor. The biogas composition was controlled using gas analyzer. 


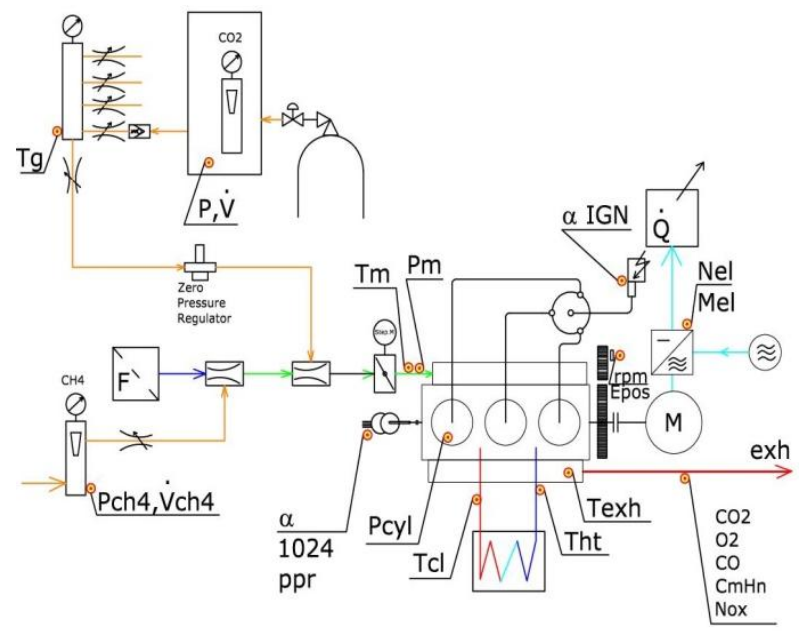

$\mathrm{T}_{\mathrm{g}}-$ gas temperature, $\mathrm{T}_{\mathrm{m}}-$ air-gas mixture temperature, $\mathrm{T}_{\mathrm{cl}}$ - engine coolant input temperature, $\mathrm{T}_{\mathrm{ht}}$ - engine coolant output temperature, $\mathrm{T}_{\text {exh }}-$ exhaust temperature, $\mathrm{P}-\mathrm{CO}_{2}$ pressure, $\mathrm{Pch} 4-\mathrm{CH}_{4}$ pressure, $\mathrm{P}_{\text {cy }} \mathrm{l}-$ in cylinder pressure, $\mathrm{N}_{\mathrm{el}}$ - electric power, exh - exhaust gas composition, $\alpha 1024 p p r$ - encoder resolution, $\alpha$ IGN ignition advance angle control system.

Figure 1. Schematic of the test bench-major components, control and measuring equipment.

The engine test bench has a cooling system for engine lubrication and cooling liquids. Within the cooling system two plate heat exchangers connected to the valves have been employed. Controlling thermostat is located in the primary circuit of the engine cooling system. The settings of the control valves on the secondary side of the heat exchangers allow to adjust the amount of the removed heat, which is then transmitted to the local central heating system. In this way, the stabilization of the engine temperature in the range of $80 \pm 5^{\circ} \mathrm{C}$ can be assured.

\subsection{The Experiment}

The experimental investigation of the natural gas and biogas combustion in SI engine were carried out in two stages. During the first stage of experimental test the engine was fuelled with natural gas coming from the gas grid. At the second stage the biogas was simulated by mixing natural gas (type GZ-50, coming from local grid) and carbon dioxide supplied from a gas cylinder. The simulated biogas applied in the engine lab tests consisted of $60 \%$ of methane and about $40 \%$ of carbon dioxide which is a typical biogas composition according to literature (Leszczynski et al., 1997; Porpatham et al., 2008; Tien et al, 2010). Other components that may appear in the real biogas represent an insignificantly small fraction of the total and are not considered in the current plan of experiment.

During the first stage of experiment the engine was powered using electric motor in order to achieve an appropriate oil and cooling liquid temperature. After the engine warm up and thermal parameters stabilization, the gas-air mixture was introduced in the system. During the engine operation stage the electric motor was switched to generator mode using automatic control system. The stabilization of the load was carried out using the power inverter braking resistor. The experiments were performed at constant rotational speed of $r_{\mathrm{o}}=1500 \mathrm{rpm}$. The study was conducted for the full engine load (i.e. wide open air throttle). The engine operation control factors represent ignition advance angle (ignition timing) and composition of the gas-air mixture. In view of the fact that the engine combustion chamber is not subject to any modifications in the first place the maximum value of excess air ratio at which the operation of the internal combustion engine is stable and there is no "misfire" detected, was checked.

During the preliminary tests, stable operation was achieved at the maximum of $\lambda=1.35$ for biogas and $\lambda=1.5$ for natural gas. It was assumed that these values will be the maximum limit of the excess air ratio throughout the experimental tests. The ignition advance angle was regulated in the range between $10 \mathrm{deg}$ and $50 \mathrm{deg}$ of the crankshaft rotation before the piston reaches top dead centre (TDC). The minimum value of the ignition advance angle has been adopted based on preliminary tests, as a result of the stable operation of the engine at selected air-gas mixture (fixed excess air ratio). The maximum value was assumed according to the literature (Leszczynski et al., 1997).

The pressure measurements in the first cylinder were performed using piezoelectric pressure transducer. This type of transducer through so called charge amplifier generates an analogue (voltage) pressure signal which is then sampled at a sufficient frequency by the data acquisition system. In addition, the absolute pressure within the intake manifold was recorded with piezoresistive absolute pressure transducer. At both measurement ducts the pressure signal was sampled at predefined crank angle using encoder. Measurements were carried out with a resolution of 1024 measurement points per revolution of the crankshaft. The encoder was also equipped with a position marker device for indicating the position of a piston in a cylinder. Each sets of measurement consisted of 100 consecutive engine cycles. Additional parameters measured during experiment include:

- Flow rate and composition of the gas;

- Pressure and temperature of the gas powered the engine;

- Temperature of the oil and engine cooling liquid,

- Ambient parameters (temperature, pressure, relative humidity);

- Exhaust gas temperature;

- Exhaust gas composition (dry products).

It should be noted that the engine was not equipped with the exhaust emission control system. Therefore, the composition of the exhaust gas was measured directly at the outlet of the exhaust system.

\subsection{In-Cylinder Pressure and Heat Release Rate}

The basic diagram that illustrates the operation of the SI engine can be created directly based on the measured incylinder pressure. In Figures 2, 3 and 4 the impact of spark ignition timing and excess air ratio on in-cylinder pressure profile of the SI engine fuelled with natural gas and biogas is presented.

The range of the ordinate axis has been selected specifically to show the compression, combustion and expansion stages of the working medium in the engine cylinder. The comparison of in-cylinder maximum pressure pmax, for investigated fuels and all engine conditions are shown in Figures 5 and 6. In all cases, the pressure in the cylinder obtained during the combustion of natural gas is higher when compared to biogas. This is mainly due to the higher LHV of natural gas and increased ignition delay of biogas. Location of the crank angle for $p_{\max }$ is presented in Figures 7 and 8. 

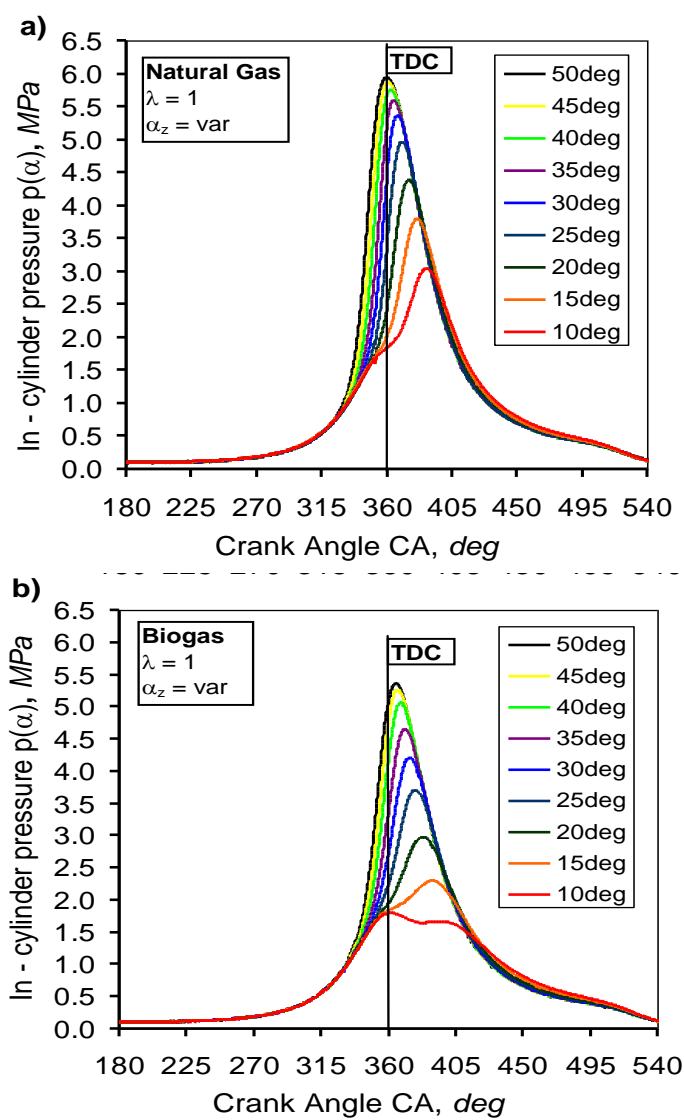

Figure 2. In-cylinder pressure $(\lambda=1, \alpha z=$ var, a) natural gas, b) Biogas).
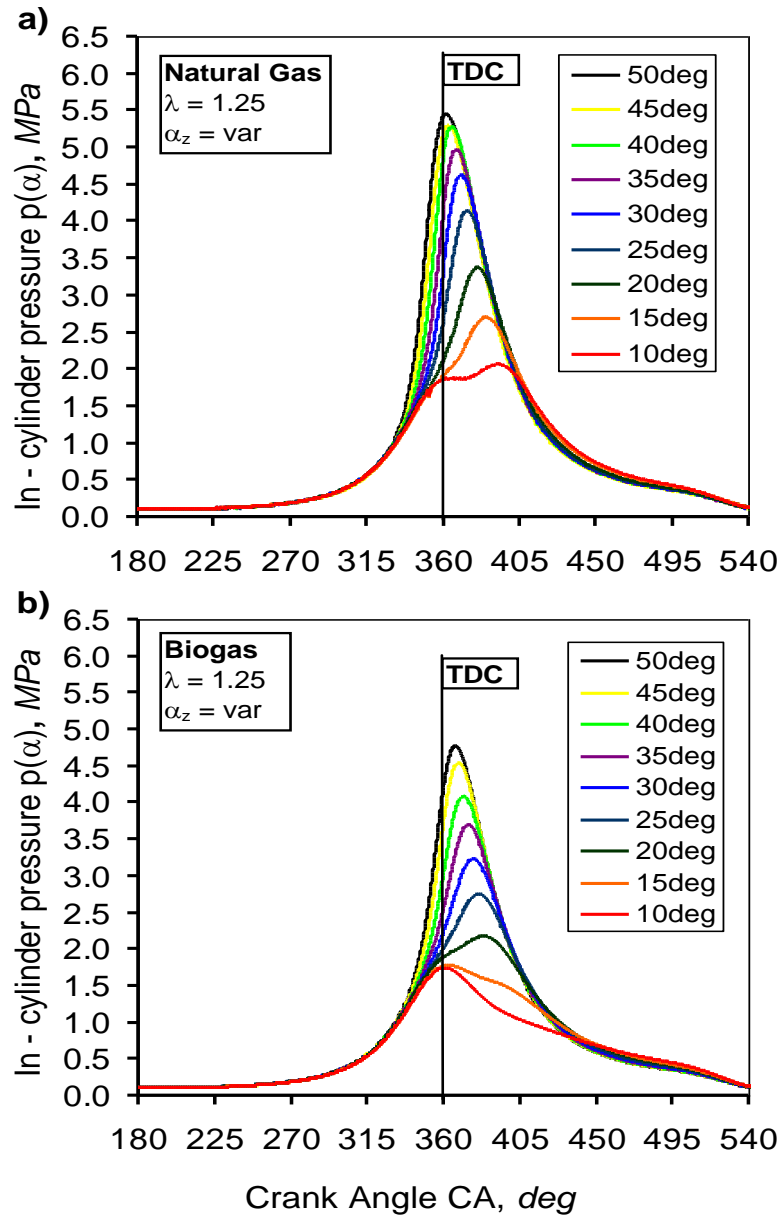

Figure 3. In-cylinder pressure $(\lambda=1.25, \alpha z=v a r, a)$ natural gas, b) Biogas).
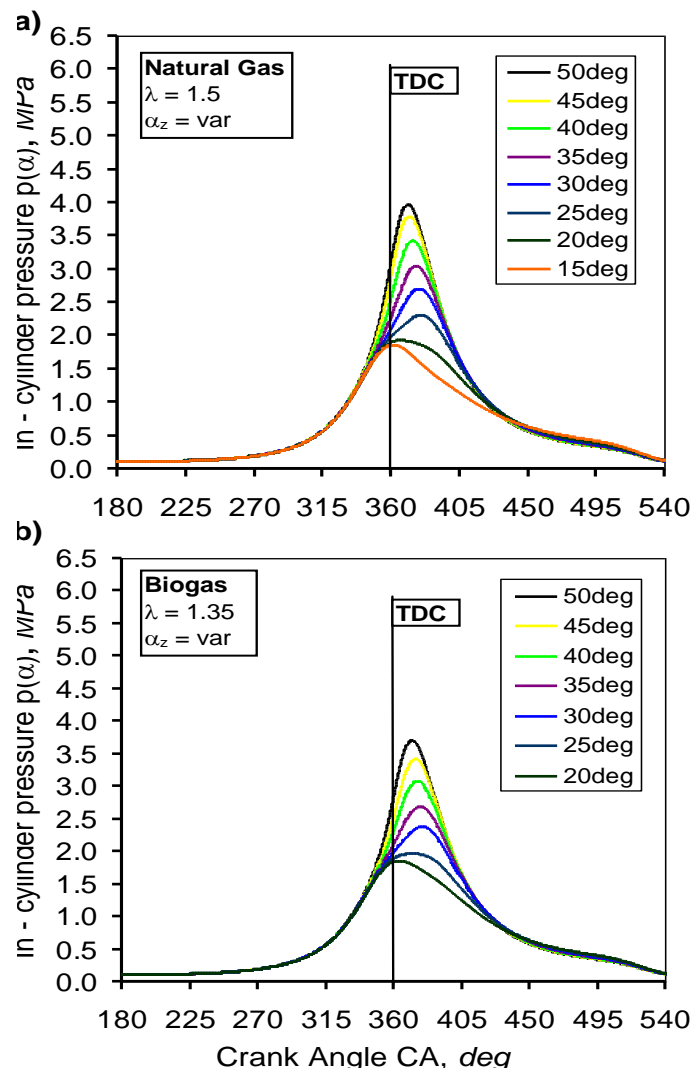

Figure 4. In-cylinder pressure $(\alpha z=v a r, a)$ natural gas, $\lambda=1.5, b)$ Biogas $\lambda=1.35$ ).

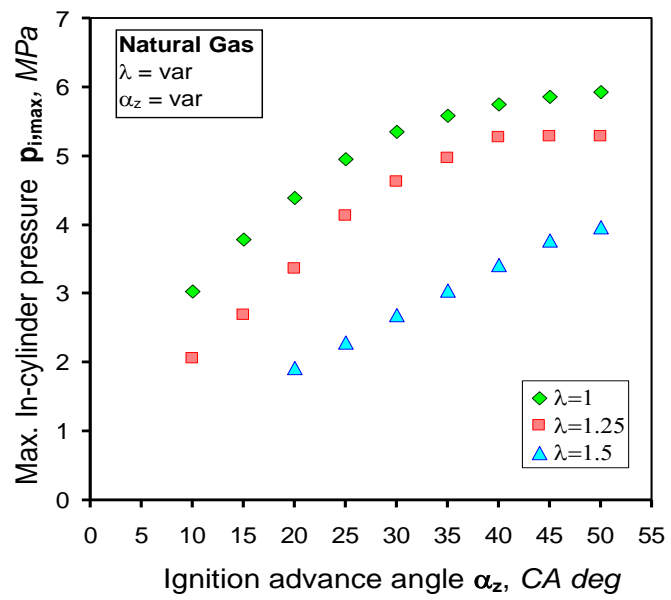

Figure 5. In-cylinder maximum pressure, engine fuelled with natural gas $(\lambda=$ var $)$.

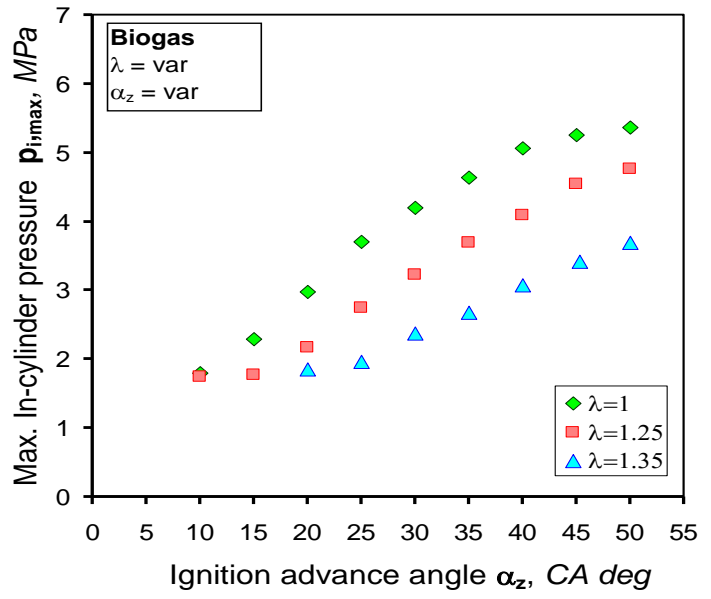

Figure 6. In-cylinder maximum pressure, engine fuelled with Biogas $(\lambda=$ var $)$. 


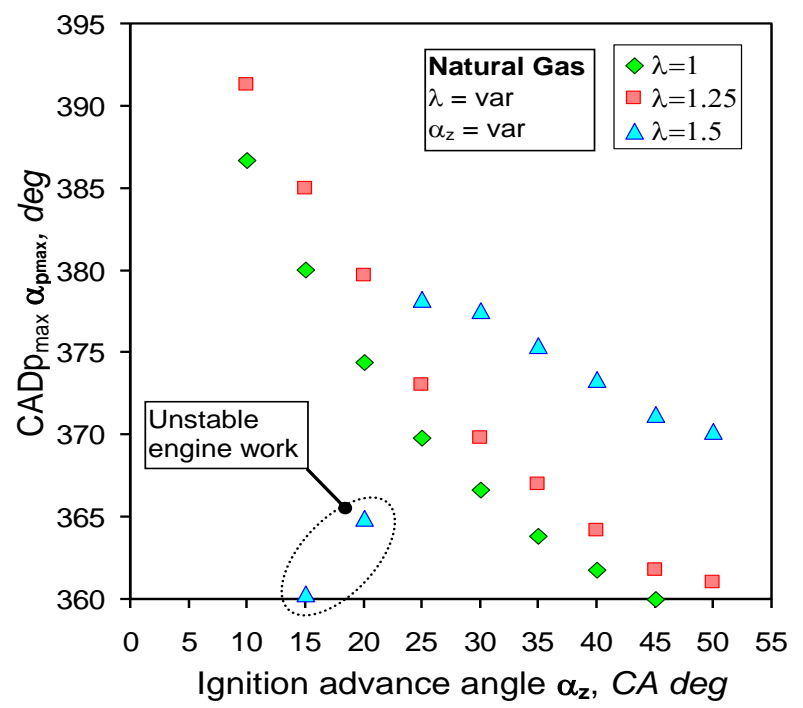

Figure 7. $C A D$ of in-cylinder $p_{\max }$, engine fuelled with natural gas $(\lambda=$ var $)$.

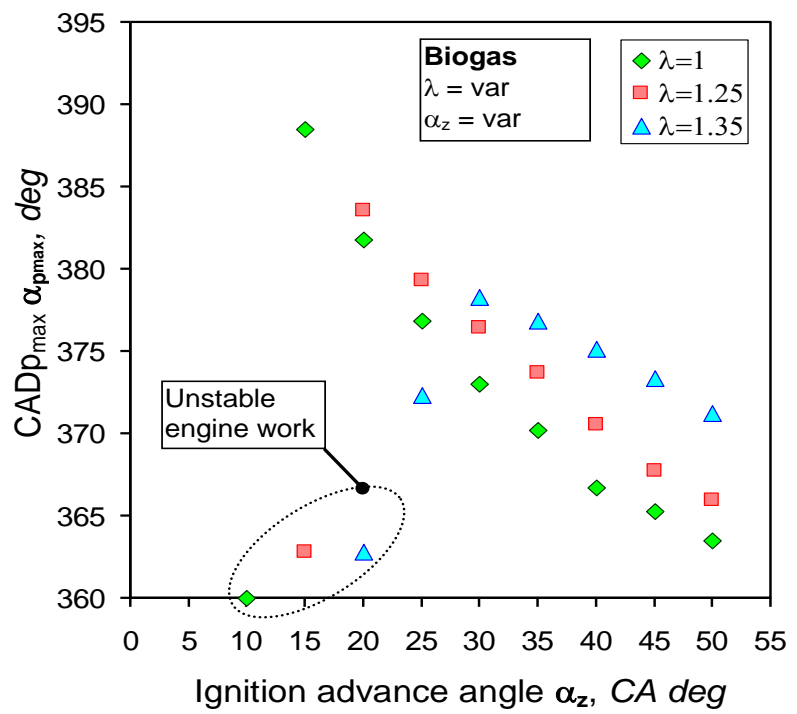

Figure 8. CAD of in-cylinder $p_{\max }$, engine fuelled with Bio'gas $(\lambda=$ var $)$.

The application of the very lean mixtures (adopted in the engine experiment) caused a limitation in the ignition advance range for both tested fuels. Thus, the stable operation of the engine was achieved at higher values of ignition timing.

The analysis of the experimental data shows that the change in spark ignition timing has a substantial influence on the in-cylinder pressure profile, mainly during the combustion and expansion stage of the engine cycle. This is caused by two different mechanisms which overlap in different proportions. The first mechanism of pressure increase in cylinder independent of ignition timing (nearly constant amount of working medium in cylinder in each cycle) is a compression of the working medium associated with heat dissipation. The second mechanism is a progressive process of combustion and the associated with heat generation. Earlier spark advance results in greater mutual overlap of both mechanisms and leads to a more intensive raise in pressure in the system.

It should be noted that the in-cylinder pressure profile determines the rate and characteristic of the overall working medium temperature. Figures 9 and 10 illustrate the impact of the engine control parameters on the maximum value of the average cylinder temperature.

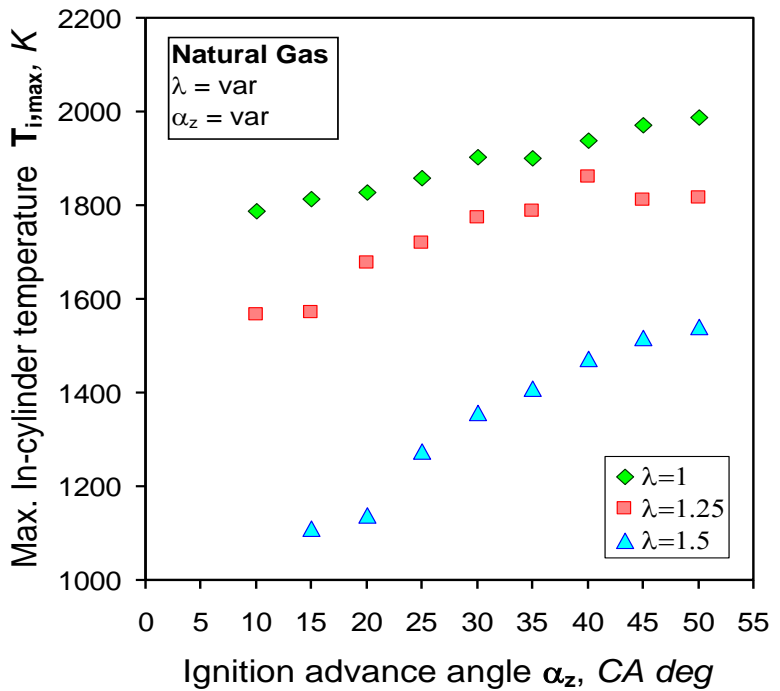

Figure 9. In-cylinder maximum temperature, engine fuelled with natural gas $(\lambda=$ var $)$.

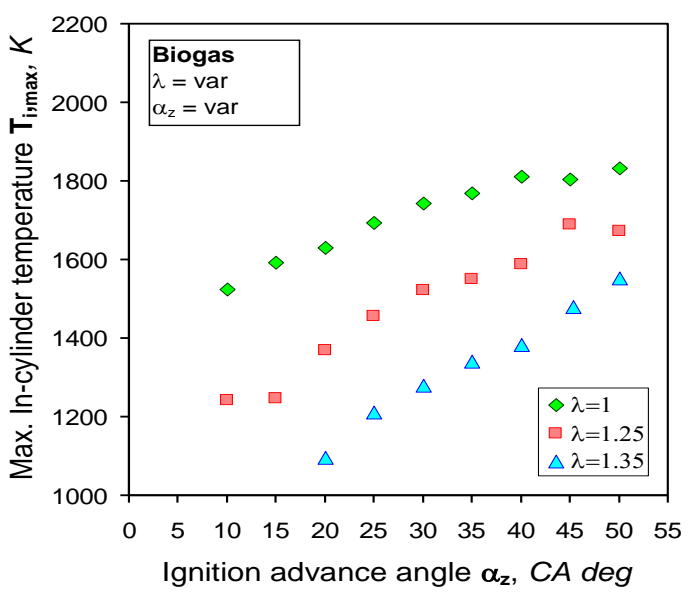

Figure 10. In-cylinder maximum temperature, engine fuelled with Biogas $(\lambda=$ var $)$.

The temperatures were computed using the equation of state for the ideal gas. It is assumed that considering the value thermal parameters of the engine cylinder this approach is sufficient and has been precisely verified in literature (Przybyla \& Postrzednik, 2006).

The above results clearly show the impact of the spark ignition timing, type of fuel and the mixture composition on the results obtained for the temperature.

For all cases studied, the earlier ignition relative to TDC contributes to higher temperatures in the cylinder. This is directly related to the in-cylinder pressure profile. Therefore, it can be assumed that higher spark advance combined with the stoichiometric mixtures combustion contributes to increased $\mathrm{NO}_{\mathrm{x}}$ emissions. The results show similar temperatures for natural gas and biogas for the leanest mixtures ( $\lambda=1.35$ - biogas, $\lambda=1.5$ - natural gas $)$. This is due to the comparable calorific value of the air-gas mixtures $\left(e d_{, v}\right)$.

A comparison of the heat release rate (HRR) for the selected points of engine fuelled with natural gas and biogas is given in Figures 11a and 11b. The presented values of the HRR were calculated for the spark ignition timing which corresponds to the maximum internal efficiency of the engine. Key included on the diagram indicates the excess air ratio while the value of the ignition advance angle is shown directly against the HRR function. 

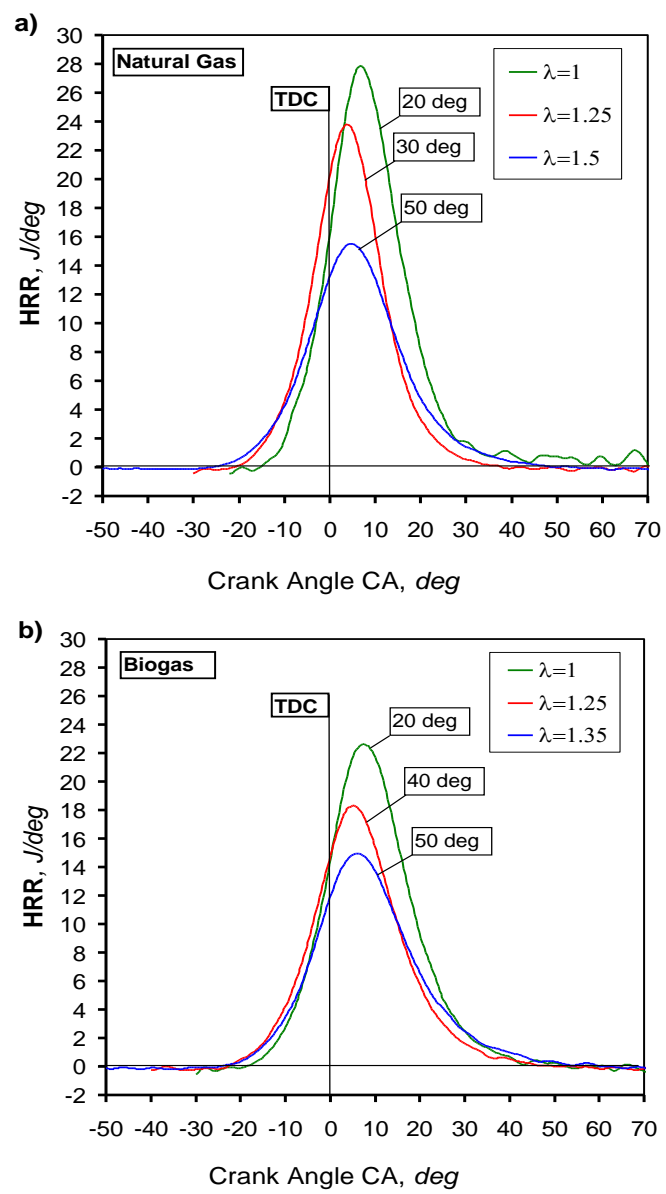

Figure 11. a) Net Heat Release Rate a function of crank angle, engine fuelled with natural gas $(\lambda=v a r), b)$ Net Heat Release Rate a function of crank angle, engine fuelled with Biogas $(\lambda=$ var).

A comparison of the HRR profiles indicates good qualitative agreement for both fuels tested and selected gasair mixtures. The notable differences can be seen in the position of the maximum HRR value relative to TDC. Table 2 illustrates the values of the rotation angle of a crankshaft $\mathrm{CA}_{(\mathrm{HRRmax})}$ corresponding to the maximum HRR position relative to TDC. For all cases, these values are expressed in terms of crank angle degree (CAD) after TDC.

Table 2. The Main Properties of Tested Fuels.

\begin{tabular}{lcccccc}
\hline Fuel & \multicolumn{3}{c}{ Natural Gas } & \multicolumn{3}{c}{ Biogas } \\
\hline $\begin{array}{l}\text { Excess air ratio } \\
\lambda \text { - }\end{array}$ & 1 & 1.25 & 1.5 & 1 & 1.25 & 1.35 \\
$\begin{array}{l}\text { Advance angle } \\
\boldsymbol{\alpha}_{\mathbf{z}} C A D b T D C\end{array}$ & 20 & 30 & 50 & 30 & 40 & 50 \\
$\mathbf{C A}\left(\mathbf{H R R}_{\max }\right)$, & 6.8 & 3.8 & 4.8 & 7.3 & 5 & 5.9 \\
$\begin{array}{l}C A D a T D C \\
\mathbf{H R R}_{\max } J / d e g\end{array}$ & 27.9 & 23.8 & 15.5 & 22.6 & 18.3 & 15 \\
\hline
\end{tabular}

The quantitative examination of the HRR profiles for tested fuels and selected gas-air mixtures indicate variations in the maximum values. These discrepancies are mainly due to the different calorific values of the studied air - gas mixtures. The value of HRR is equal to approximately 5.5 $\mathrm{J} / \mathrm{deg}$ for both mixtures at $\lambda=1$ and $\lambda=1.25$. It has been mentioned earlier that similar calorific value $\left(\mathrm{e}_{\mathrm{d}, \mathrm{v}}\right)$ can be observed for biogas mixture at $\lambda=1.35$ when compared with the mixture of natural gas at $\lambda=1.5$. Therefore, the maximum values of the heat generated in the cylinder $\left(H R R_{\max }\right)$ are comparable for those mixtures, and their specific values are presented in Table 2.

\subsection{Engine Performance}

In this paper, the indicated efficiency and internal mean effective pressure (IMEP) are considered the key parameters affecting the operation of the engine. Figures 12 and 13 show the impact of ignition advance angle and excess air ratio $\lambda$ on the indicated efficiency when using natural gas and biogas, respectively. From the results, it can be concluded that the value of the engine indicated efficiency varies primarily with the spark ignition timing. The combustion of lean mixtures is characterized by higher engine maximum efficiency compared to stoichiometric mixtures. Therefore, an appropriate selection of the ignition advance angle is crucial, depending on the type of fuels and the air-fuel mixtures applied in the system.

Comparison between Figures 12 and 13 did not indicate significant variations in the levels of indicated efficiency for the engine fuelled with biogas and natural gas. Effective combustion of biogas requires the use of higher ignition advance angle (by about $10 \mathrm{CAD}$ ) in contrast with natural gas combustion. Furthermore, it can be observed that the leaner mixture is used, the higher values of ignition advance angle should be selected in order to achieve high engine efficiency. The set of results for $\lambda=1$ and $\lambda=1.25$ show distinct extrema where the indicated efficiency reaches its maximum. In contrast, the results obtained for very lean mixtures i.e. $\lambda=1.35$ (biogas) and $\lambda=1.5$ (methane) did not show any particular extrema. The ignition advance angle adopted in the experimental test with the maximum value equal to $50 \mathrm{deg}$ before TDC corresponds to maximum engine efficiency. Unfortunately, within the scope of experiment it was not possible to confirm whether this value corresponds to extremum engine efficiency.

The influence of the engine control parameters on Indicated Mean Effective Pressure (IMEP) is presented in Figures 14 and 15 for natural gas and biogas mixtures, respectively.

As can be observed, the IMEP profile exhibits similar trend with the indicated efficiency if comparing the location of the IMEP maximum value regarding to the spark advance.

For the lean mixtures the highest values of IMEP occur for increased ignition advance value. The one reason is that the combustion time of lean mixtures is longer in comparison with the stoichiometric mixture. In this case, location of the phasing when the main burn period occur $(10-90 \% \mathrm{MFB})$ is very important. To obtain optimal values of $10-90 \%$ MFB of the lean mixtures, the ignition timing has to be advanced.

Unlike the stoichiometric mixtures, the combustion of lean mixtures leads to reduction in IMEP values.It has been pointed out earlier that this is mainly due to a decrease in the heating value $\left(\mathrm{e}_{\mathrm{d}, \mathrm{v}}\right)$ of the air-fuel mixture as the excess air ratio is increased.

In Figures 16-21, the experimental results for carbon monoxide (eCO), nitrogen oxides (eNOx) and total hydrocarbons (eTHC) emission indices have been plotted against the change in ignition advance angle and excess air ratio. In order to get comparable results all emission indices were converted into an internal work of the engine. These values can be converted to useful effect, i.e. the value of the work on the crankshaft of the engine. However, for the analysis of the specific cogeneration system, these indices should be converted into electric energy. 


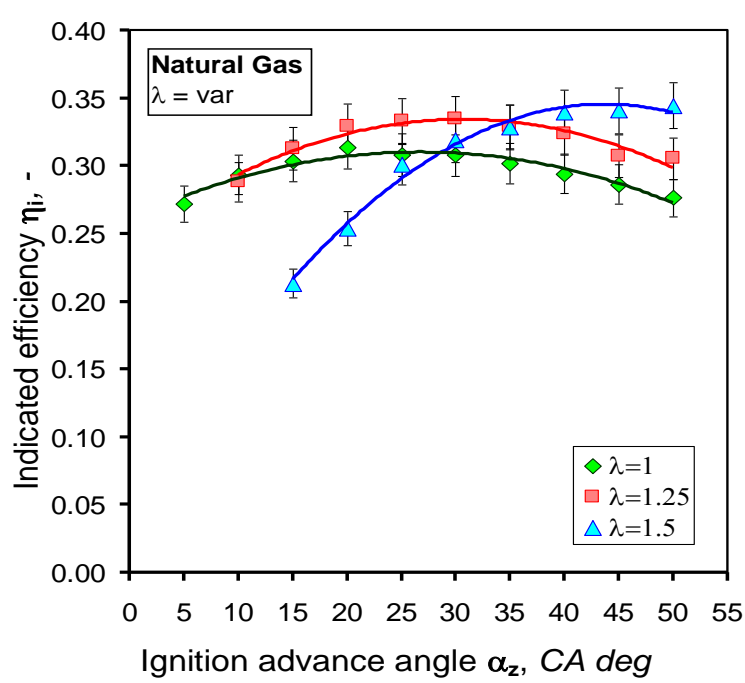

Figure 12. Indicated efficiency as a function of spark ignition timing engine fuelled with natural gas $(\lambda=v a r)$.

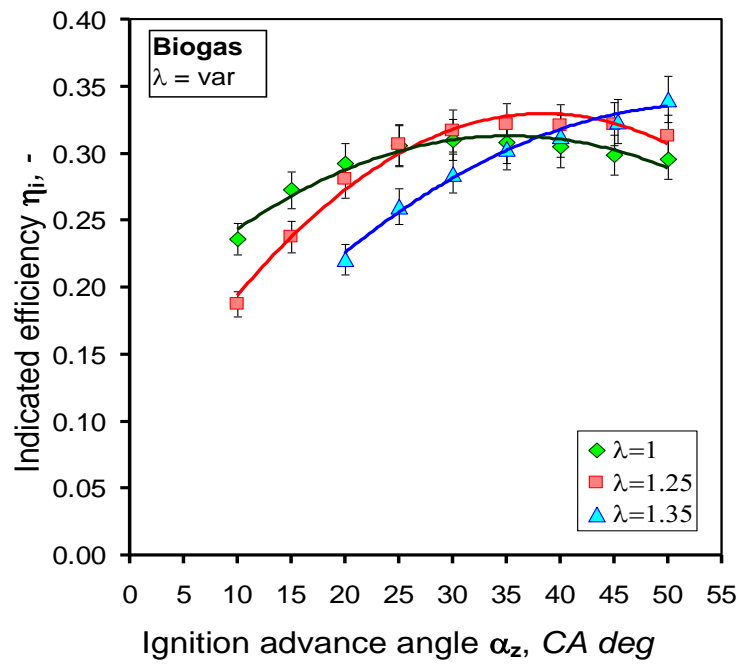

Figure 13. Indicated efficiency as a function of spark ignition timing, engine fuelled with Biogas $(\lambda=v a r)$.

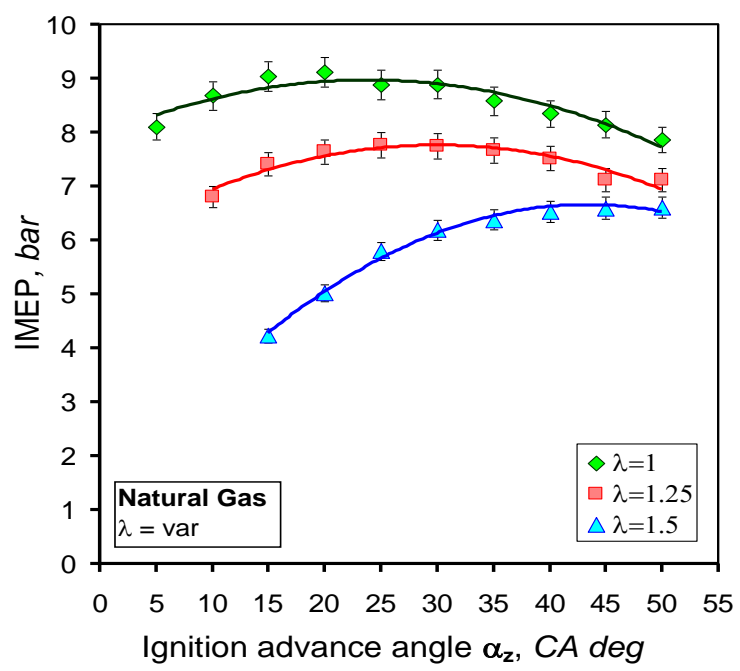

Figure 14. Indicated mean effective pressure (IMEP), engine fuelled with natural gas $(\lambda=v a r)$.

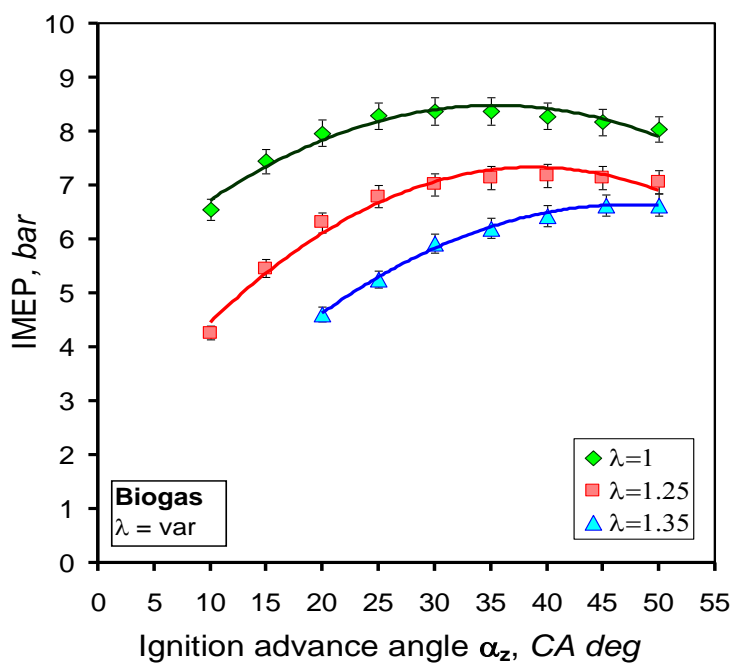

Figure 15. Indicated mean effective pressure (IMEP), engine fuelled with Biogas $(\lambda=$ var $)$.

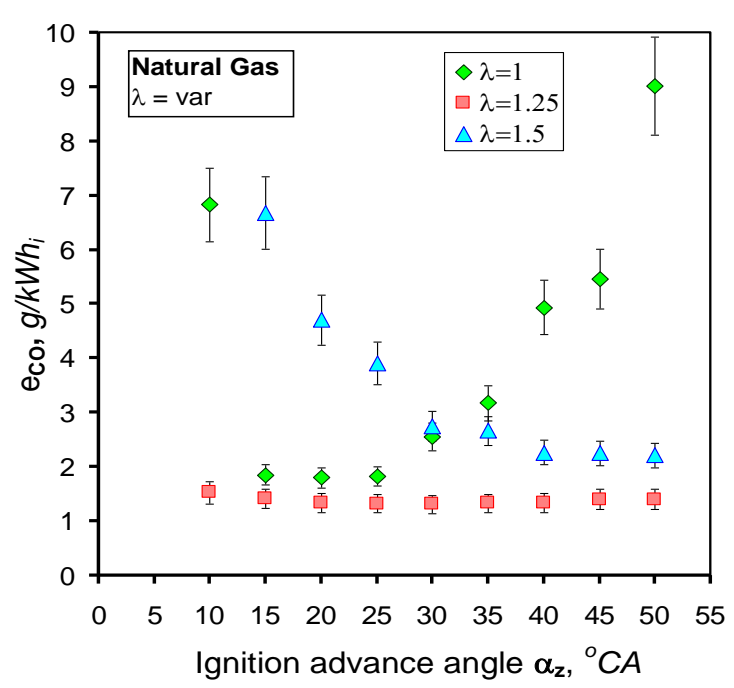

Figure 16. Emission index $e_{C O}$, engine fuelled with natural $\operatorname{gas}(\lambda=\operatorname{var})$.

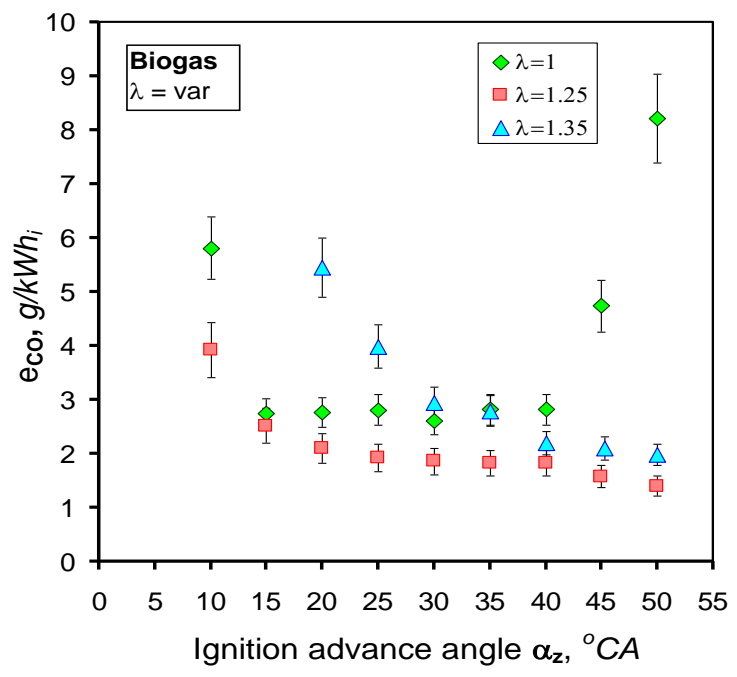

Figure 17. Emission index $e_{C O}$, engine fuelled with Biogas $(\lambda=v a r)$. 


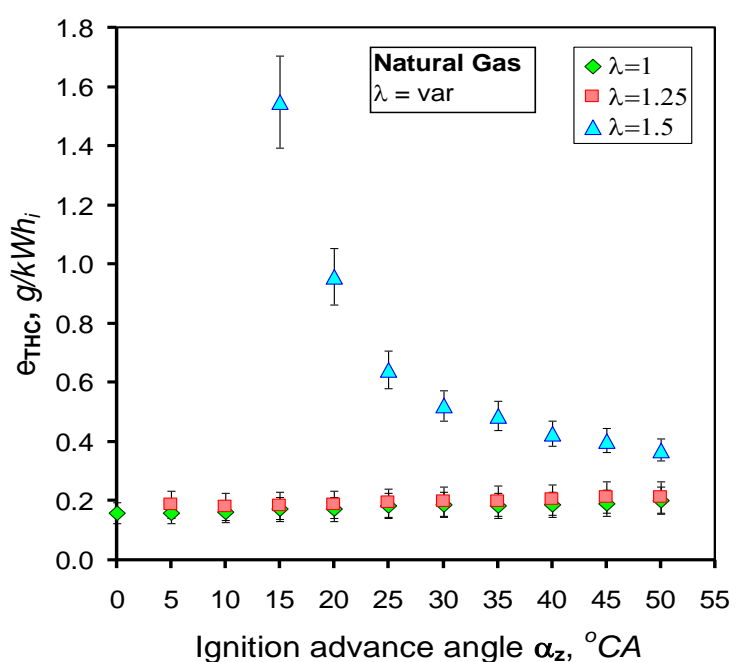

Figure 18. Emission index $e_{T H C}$, engine fuelled with natural $\operatorname{gas}(\lambda=$ var $)$.

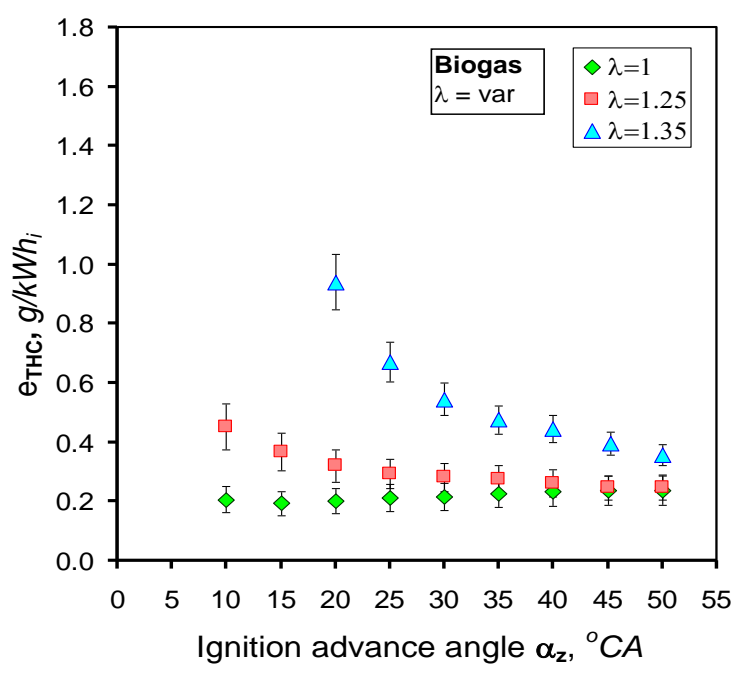

Figure 19. Emission index $e_{T H C}$, engine fuelled with Biogas $(\lambda=$ var $)$.

The subject of the research is an internal combustion engine connected to an electric motor dynamometers (only an inhibitory element, not an electricity generator). Therefore, it would be ambiguous to relate emissions to the value of electrical energy generated by an electric motor which works in generator mode.

It can be seen in Figures 12-13 that for the lower values of ignition advance angle the level of carbon monoxide emissions depends primarily on the excess air ratio. Whereas, in the case of stoichiometric combustion, higher $\mathrm{CO}$ emissions occur in a range of greater values of ignition advance angle. The advantageous feature of the results is the reduction in $\mathrm{CO}$ emissions for lean mixtures combustion at ignition advance angle values corresponding to maximum engine efficiency, i.e. between $40^{\circ}$ and $50^{\circ}$ of the crankshaft rotation before the piston reaches TDC. It is surprising that for the combustion of natural gas at $\lambda=1.25$ the level of $\mathrm{e}_{\mathrm{CO}}$ is nearly constant.

The total hydrocarbons emission index $\left(\mathrm{e}_{\mathrm{THC}}\right)$ profiles as a function of ignition advance angle for natural gas and biogas are presented in Figures 14 and 15, respectively. As can be observed, the THC emission index results are qualitatively similar to carbon monoxide profiles. The experimental results show a minor increase in THC emissions for biogas combustion.

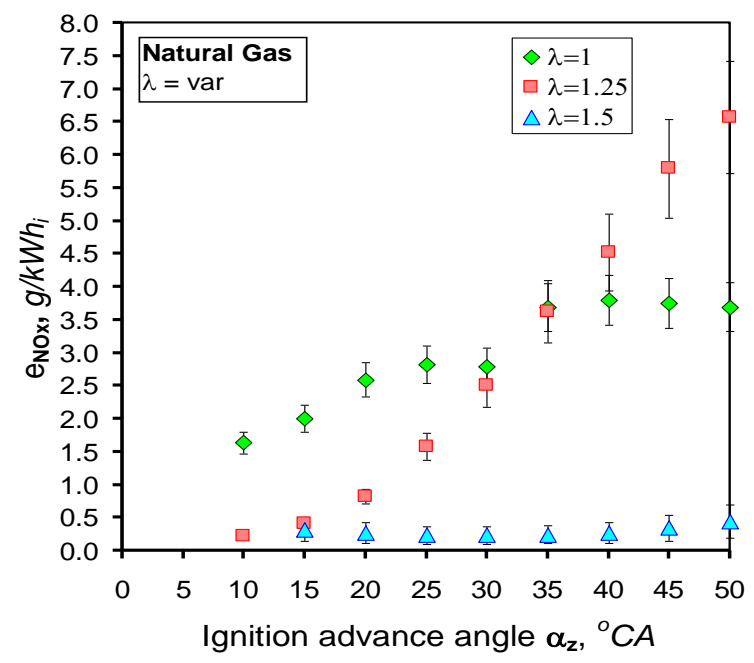

Figure 20. Emission index $e_{N O x}$, engine fuelled with natural $\operatorname{gas}(\lambda=v a r)$.

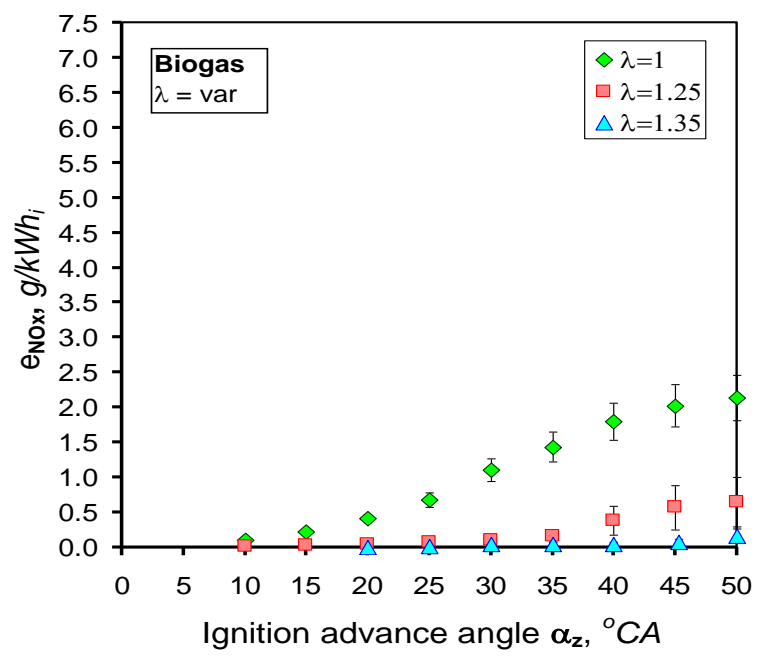

Figure 21. Emission index $e_{N O x}$, engine fuelled with Biogas $(\lambda=$ var $)$.

The effect of control parameters on the NOx emission index $\left(\mathrm{e}_{\mathrm{NOx}}\right)$ is shown in Figures 16 and 17. Unlike the $\mathrm{CO}$ and THC profiles, the NOx emission fractions exhibit different characteristic. As can be observed, higher level of NOx emissions correspond to the greater values of ignition advance angle. On the other hand, the combustion of lean mixtures lead to considerable reduction in NOx emissions, in particular for higher values of the ignition advance angle. This is directly attributed to the pressure characteristic and corresponding maximum temperature in cylinder. High ignition advance causes an increase in maximum temperature and consequently contributes significantly to the total formation of nitrogen oxides. The combustion of lean mixtures causes maximum temperature to drop during combustion (relative to mixtures with higher $\lambda$ ). It is interesting to observe that during the combustion of natural gas at $\lambda=1.25$ and the ignition advance angle greater than $35 \mathrm{deg}$, the $\mathrm{NO}_{\mathrm{x}}$ emissions are higher than that of stoichiometric mixture. Assuming that the formation of $\mathrm{NO}_{\mathrm{x}}$ in SI engines is determined mainly by the thermal mechanism, it is anticipated that, within the current range of engine operating conditions the local cylinder temperatures are higher when compared to stoichiometric mixtures. A summary of major parameters related to the experiment, including the maximum values of indicated efficiency and 
indicated mean effective pressure (IMEP) is given in Table 3.

The results indicate that the lower heating value has a minor impact on the internal combustion engine efficiency when optimal ignition advance angle value is employed. For both natural gas and biogas, the maximum of the IMEP value is the same at $\lambda=1.35$ and $\lambda=1.5$ (very lean mixtures). It should be noted that in this case the calorific value of the biogas air-fuel mixture $\left(e_{d v}\right)$ is higher compared to natural gas.

\section{Conclusions}

Experimental measurements indicate that the ignition advance angle considerably affect both the engine indicated parameters and the amount of exhaust emissions. For all sets of measurements $(\lambda=$ var), an increase in pressure and temperature in the cylinder at higher values of the ignition advance angle can be observed. Earlier ignition advance results in higher pressure in the system due to the greater mutual overlap between the compression and heat generation.

Table 3. The $\left(e_{d v}\right)$ Value and Engine Performance Results.

\begin{tabular}{lcccccc}
\hline Fuel & \multicolumn{3}{c}{ Natural Gas } & \multicolumn{3}{c}{ Biogas } \\
\hline Excess air ratio $\boldsymbol{\lambda},-$ & 1 & 1.25 & 1.5 & 1 & 1.25 & 1.35 \\
Advance angle $\boldsymbol{\alpha}_{\mathbf{z}}$, & 20 & 30 & 50 & 30 & 40 & 50 \\
$C A D b$ TDC & & & & & & \\
$\mathbf{p}_{\mathbf{i}, \max }, \mathrm{MPa}$ & 4.39 & 4.69 & 3.96 & 4.2 & 4.54 & 3.7 \\
$\mathbf{t}_{\mathbf{i}, \mathbf{m a x}},{ }^{\circ} \mathrm{C}$ & 1828 & 1774 & 1542 & 1744 & 1689 & 1553 \\
$\mathbf{t}_{\mathbf{e x}},{ }^{\circ} \mathrm{C}$ & 620 & 524 & 451 & 597 & 500 & 472 \\
$\eta_{\mathbf{i}, \mathbf{m a x}}, \%$ & 31.3 & 33.4 & 34.5 & 31 & 32.2 & 34 \\
$\mathbf{I M E P}_{\mathbf{m a x}}$, bar & 9.1 & 7.7 & 6.6 & 8.4 & 7.1 & 6.6 \\
$\mathbf{e}_{\mathbf{d v}}, \mathrm{MJ} / \mathrm{m}^{3} \mathrm{n}$ & 3.4 & 2.77 & 2.34 & 3.2 & 2.64 & 2.46 \\
$\mathbf{e}_{\mathbf{C O}}, \mathrm{g} / \mathrm{kWhi}$ & 1.8 & 1.31 & 2.21 & 2.61 & 1.58 & 1.98 \\
$\mathbf{e}_{\mathbf{T H C}}, \mathrm{g} / \mathrm{kWhi}$ & 0.172 & 0.199 & 0.373 & 0.217 & 0.246 & 0.355 \\
$\mathbf{e}_{\mathbf{N O x}}, \mathrm{g} / \mathrm{kWhi}$ & 2.59 & 2.5 & 0.44 & 1.11 & 0.57 & 0.16 \\
\hline
\end{tabular}

It has been demonstrated that lean fuel mixtures take longer to burn when compared to stoichiometric mixtures. Therefore, in the case of lean combustion it is necessary to use higher values of ignition advance angles. Furthermore, the combustion of biogas requires the use of increased values of the ignition advance angle by about $10 \mathrm{deg}$ in comparison to natural gas.

An interesting conclusion can be drawn from the predictions for the indicated efficiency. The results demonstrate that combustion of lean air-gas mixtures leads to higher values of indicated efficiency when compared with stoichiometric mixtures. Additionally, for both fuels an increase in indicated efficiency is observed for higher values of ignition advance angle.

As expected the level of emissions from the engine is sensitive to the engine control parameters and operating conditions. Higher values of the ignition advance angle lead to an increase in $\mathrm{NO}_{\mathrm{x}}$ emissions. Furthermore, a drop in nitrogen oxides can be observed for lean mixtures. The results for both natural gas and biogas indicate the lowest level of $\mathrm{CO}$ at excess air ratio $\lambda=1.25$. For the stoichiometric mixtures the highest $\mathrm{CO}$ emissions are observed at higher ignition advance angle.

The sharp increase in the $\mathrm{CO}$ emission index at $10 \mathrm{deg}$ (stoichiometric condition) evaluated for both the fuels can be caused by unstable combustion process. For this value of ignition timing the value of coefficient of variation of indicated work reached highest values.

It can be concluded that emission fractions of THC and $\mathrm{CO}$ measured at maximum efficiency show similar level for both fuels under investigation (see Table 2). The $\mathrm{NO}_{\mathrm{x}}$ emissions are lower for biogas as illustrated by comparison in Table 2. This is mainly due to lower average temperatures in the cylinder when engine was fuelled with biogas.

\section{Acknowledgements}

This work is financed by the National Centre for Research and Development (NCBiR) and ENERGA S.A. under Grant by the Strategic scientific research and experimental development program: „Advanced technologies of acquiring energy", Task nr 4 "Development of integrated technologies for production of fuels and energy from biomass, agricultural waste and other materials".

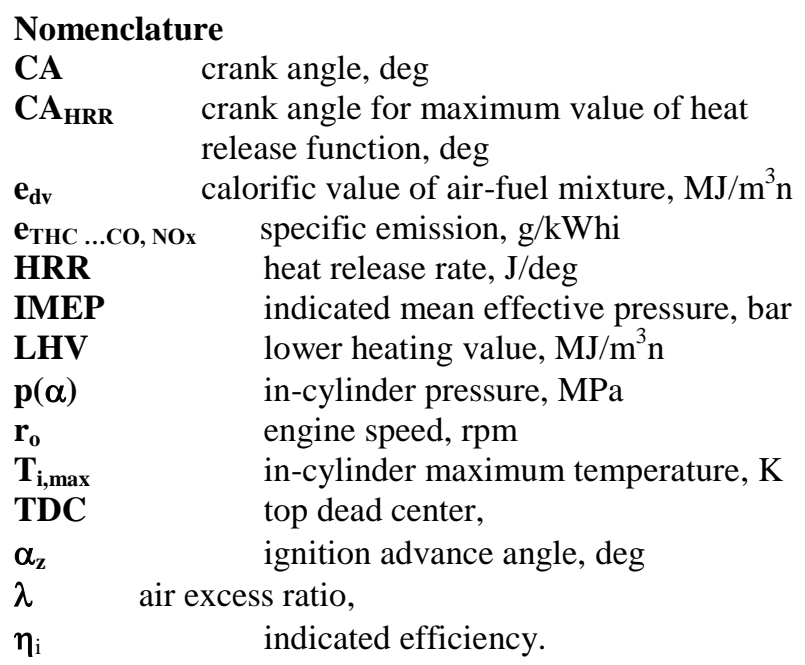

\section{References}

Adhikari B. K., Barrington, S., Martinez, J. (2006). Predicted Growth of World Urban Food Waste and Methane Production. Waste Management \& Research, 24, 421-433.

Ayala, F. A., Gerty, M. D., Heywood, J. B. (2006), Effects of Combustion Phasing, Relative Air-fuel Ratio, Compression Ratio, and Load on SI Engine Efficiency. SAE Technical Paper. 2006-01-0229,

Berggren, M., Ljunggren, E., Johnsson, F. (2008). Biomass Co-Firing Potentials for Electricity Generation in Poland-Matching Supply and Co-Firing Opportunities. Biomass and Bioenergy, 32, 865-879.

Bade Shrestha, S.O., Narayanan, G. (2008). Landfill Gas with Hydrogen Addition - A Fuel for SI Engines. Fuel, 87, 3616-3626.

Curry, N., Pillay, P. (2012). Biogas Prediction and Design of a Food Waste to Energy System for the Urban Environment. Renewable Energy, 41, 200-209.

Das, L. M., Gulati R., Gupta P. K. (2000). A Comparative Evaluation of the Performance Characteristic of a Spark Ignition Engine Using Hydrogen and Compressed Natural Gas. Int. J. Hydrogen Energy, 25, 783-793.

Heywood, J. B. (1988). Internal Combustion Engine Fundamentals, First Ed. New York: McGraw-Hill.

Igliński, B., Iglińska, A., Kujawski, W., Buczkowski, R., Cichosz, M. (2011). Bioenergy in Poland. Renewable and Sustainable Energy Reviews, 15, 2999- 3007. 
Leszczynski, S., Brzychczyk, P., Sekula, R. (1997). Review of Biomass as a Source of Energy for Poland. Energy Sources, 19, 845-850.

Mancaruso, E., Sequino, L., Vaglieco, B. M. (2011). First and Second Generation Biodiesels Spray Characterization in a Diesel Engine, Fuel, 90, 28702883.

McKendry P. (2002). Energy Production from Biomass (Part 2): Conversion Technologies. Bioresource Technology, 83, 47-54.

Porpatham, E., Ramesh, A., Nagalingam, B. (2008). Investigation on the Effect of Concentration of Methane in Biogas when Used as a Fuel for a Spark Ignition Engine. Fuel, 87, 1651-1659.

Poulsen, P. H. B., Magid, J., Luxhøi, J., Neergaard, A. (2013). Effects of Fertilization with Urban and Agricultural Organic Wastes in a Field Trial - Waste Imprint on Soil Microbial Activity. Soil Biology and Biochemistry, 57, 794-802.

Przybyla, G., Postrzednik, S. (2006). Purposefulness of Using Real Gas Model in Analysis of Internal
Combustoin Engine Cycle Parameters. Journal of KONES, 13, 315-322.

Silva, M. J., Souza, S. M. N., Chaves, L., Rosa, H. A., Secco, D., Santos, R. F., Baricatti, R. A., Nogueira, C. E. C. (2013). Comparative Analysis of Engine Generator Performance Using Diesel Oil and Biodiesels Available in Parana State, Brazil. Renewable and Sustainable Energy Reviews, 17, 278-282.

Stone R. (1999). Introduction to Internal Combustion Engines, (3rd ed.). London: MacMillan Press LTD.

Tien, T. M., Mai, P. X., Hung, N. D., Cong, H. T. (2010). A Study on Power Generation System Using Biogas Generated From the Waste of Pig Farm. 2010 International Forum on Strategic Technology (IFOST): Proceedings of IEEE, 203-207.

Weaver, C. S. (1989). Natural Gas Vehicles - A Review of the State of the Art. SAE Transactions, 98, 1190-1210.

White C. M., Steeper R. R., Lutz A. E. (2006). The Hydrogen - Fueled Internal Combustion Engine: a Technical Review. Int. J. Hydrogen Energy, 10, 12921305 . 